\title{
The opportunities and challenges of Māori agribusiness in hill farming
}

\author{
R.V. COTTRELL \\ Farm Consultant, 9 Hindmarsh Drive, Taupo, New Zealand \\ bob.cottrell@xtra.co.nz
}

\section{Introduction}

This paper is a personal view of the opportunities and challenges that face Māori hill country farms over the next 20 years. This view is based on my observations and experiences working in the Māori agribusiness sector over the last 35 years.

Māori agribusiness has come a long way in the last 50 years. The term "sleeping giant" is still relevant today. The last 30 years have seen the major land developments of the 1980s and 1990s consolidate, and many Māori land blocks came back under full Māori control. In the last 15 years there have been some major success stories across the Māori farming sector, highlighted by the revitalisation of the Ahuwhenua Awards competition in 2003.

However, a number of factors will continue to constrain many Māori hill farming enterprises over the next 10-20 years.

By far the largest proportion of Māori freehold farms are located on the hills. There are few economic options for large proportions of this land, much of which is in remote locations and on land classes at higher altitude. Forestry and more latterly industries such as Manuka honey are opportunities that owners have considered to better utilise the land and improve profits. While there is a place for both on some of our erosion prone, low production hill country and undeveloped lands, in my opinion livestock farming will still dominate much of the developed and semi-developed lands for many years to come.

Māori farmers need to adapt to the ever changing farming environment to ensure their communities thrive and grow over future generations. While this may seem difficult for many entities there are examples of success that can be learnt from.

\section{Range and state of Māori farming}

I would estimate that in excess of $70 \%$ of Māori land is located in the hills, or in remote areas. From my observations the majority of Māori owned hill farms sit in what is termed Land Use Classes 4, 6 and 7. These are mainly sheep and beef breeding units with limited finishing potential.

Māori hill country farms fall into three main groups, although it is difficult to estimate the

percentage of the total Māori land in each of these groups, the majority of hill farms sit in groups 1 and 2 :

1. Underdeveloped farms - these are entities or land parcels that have potential to develop, but lack key people resources. They require investment and skills to progress. These farms are partially developed, generate insufficient farm income and have low soil fertility and mediocre stock performance. They lack capital and skilled labour resources. Governance generally lacks the required skills and experience to make the investment required.

2. Developing farms - these are entities where the leadership, management and advisors have identified opportunities to grow their businesses and are actively engaged in developing their resources. These properties have usually incurred some level of borrowing to support a development programme and some have partnered with others to secure support and reduce risks. There is an improved level of management and advisory capacity to support governance, but there are still a range of development stages within this group. Many of these properties are improving quickly.

3. Intensifying farms - these entities are consistently performing in the upper quartiles of their land class in both profit and production. They have strong governance, good management and advisors in place and they know where they are heading. They are normally proactive in their management approach and look for opportunities to enhance their business performance. There is strong support from their ownership base and business partners. These entities are open to new technologies and innovation, but are not necessarily innovators. The people in their business are seen as an essential asset to their organisations and skills and capacity are developed and rewarded. New forages, genetics and marketing opportunities are being tested and utilised. These organisations will normally participate and invest in areas of research and development where there is value to be gained.

A fourth group has been identified that are looking to diversify beyond the farm gate. This group has developed from a collaboration of entities over time (usually from within groups 2 and 3 above), and are actively investigating opportunities to develop relationships alongside processors in the market place. 


\section{Challenges for Māori hill farmers Economic and climate}

In an ever changing economic, climatic and regulatory environment with fluctuating product prices, climatic extremes and regulatory uncertainty, hill country farming systems continue to come under pressure. For many underdeveloped and developing Māori hill country farms, this uncertainty can lead to lower profits and reduced investment in production and development.

\section{Soils and pastures}

Soil fertility is a major challenge for hill farmers generally. Not only are hill soils naturally low in fertility, but the costs of improving this fertility are high. Soil fertility is the key driver of our pasture systems which in turn drive production systems.

In my opinion, pasture systems will continue to drive our hill farming businesses. To manage these pasture systems more efficiently in future base soil fertility must be boosted to create feed for critical production periods. While other forages are being trialled on hill farms, I do not see these options as alternatives to our pasture systems any time soon.

Feeding and feed quality continue to challenge all farm systems. Māori farmers operate within an environment where the land will never be sold. Therefore, capital gain is not an option for Māori farmers and they adopt a cash flow and profit approach to farming their properties. This can sometimes put pressure on important discretionary investment expenditure like fertiliser and labour.

Where soil fertility levels have been optimised on hill farms, and subdivision and water installed, a major lift in production has occurred.

\section{Governance and business management skills}

The governance of Māori entities (Ahuwhenua Trusts and Incorporations) requires a level of leadership that embrace multiple skills. How modern farming businesses operate and the multiple drivers of farm performance are not easily understood by many of the elected representatives. Many Māori have been disconnected from their rural roots and the farm business skills are sometimes limited to only a few people within a board. Recognising this constraint, there are now some worthwhile governance workshops targeted at improving the knowledge and skills of governance boards in areas of farm business and management, strategy and planning.

\section{Farm management capability}

Modern hill farming demands skilled people to manage these businesses. These people not only require excellent husbandry skills, but competent business skills, planning skills and good skills in early decision making. Young people entering farming with these multiple skillsets are scarce and this is an industry concern. While there are institutions training people for farm management careers, in my opinion there still appears to be a lack of understanding of the knowledge and skills required. To develop robust farm systems for hill country, access to a capable labour resource is needed to ensure their success.

\section{Information systems for hill country}

Gathering accurate and regular information is a real challenge for even the most competent of farm managers. These large scale operations of $1500-2500$ ha on broken terrain have no easy and accurate way of measuring pasture and animal performance without a certain amount of estimation and averaging. For farmers to make accurate and reliable early decisions industry and research organisations need to develop cost effective and easily managed tools that can accurately assess pasture and animal performance in hill systems.

\section{Current and future regulation}

Many hill farms face current and future constraints from regulatory authorities. Issues around water quality are already affecting farms in the sensitive lake and river catchments in the Waikato, Bay of Plenty and Horizons Regional Council areas. I expect these regulatory constraints to expand nationwide over the next few years.

The current review of the Emissions Trading Scheme is looking to exclude agriculture at this stage, but this may change in the future.

The cost of any regulatory change for Māori entities will restrict their ability to farm to their full potential without some expertise and cost. Regulatory constraints to the under developed and developing Māori hill country entities will limit future economic land use opportunities to more risky and potentially marginal long term options.

\section{Marketing strategies for hill farms}

With much of hill country livestock being sold store, there is always uncertainty around the prices received. Climatic events and fluctuating product prices dictate store stock prices and there is currently no mechanism to reduce this risk for hill farmers. The genetics in many of our hill ewe flocks are capable of $150 \%$ lambing and as hill properties develop, these systems and the store stock market will face even greater risk. With hill country systems being the nursery for our prime lambs, the industry needs to find some way to develop transparent supply arrangements for hill country store stock farmers to ensure the viability of these systems. Some Māori entities have purchased alternative land 
classes to network breeding and finishing systems in an attempt to mitigate this issue.

\section{Multiple decision criteria}

While the commercial and growth aspirations of Māori entities are important, shareholders also expect that their environmental, social and cultural expectations are also balanced in the decision process. Shareholder expectations add a complexity to the priorities land governors need to consider and defend where investment decisions are being made. While this is often difficult when land is being developed and capital is scarce, many entities have managed to successfully navigate these multiple expectations through good shareholder communication and a robust planning process.

\section{Attributes of successful Māori agribusiness}

The Māori entities that have successfully developed their resources and governance are in the top performing group of hill farmers. This is evidenced by the performance of the recent finalists and winners of the Ahuwhenua trophy (Table 1).

This has not happened by chance, but by good leadership and support, good planning and plain hard work. Critical decision processes include gathering good information and discussion between managers and key advisors. There is a strong team emphasis within these organisations from owners to governance to staff and business partners. This emphasis is built around a number of core values which these organisations have established for themselves and all their relationship partners.

For these businesses, success is born out of superior longer term profitability, higher stock performance and often higher stocking rates (top 20\% of land class benchmarked). This is achieved without compromising essential and critical farm inputs like fertiliser and labour.

These successes have not come without some notable changes. Most of the changes for these entities have happened over the last 7-12 years and while fluctuating economic and climatic cycles have occurred during this time, most have continued to develop and grow their businesses. The majority of these entities have seen changes in operational management capability as well as changes in governance focus and succession, resulting in renewed long term visions and plans.

There has been structured investment in productive development, infrastructure and farm systems without losing sight of their environmental objectives and obligations. Whether this investment has been through the acquisition of additional land, further land development, or collaboration beyond the farm gate there is a continuing interest within these groups to make these businesses as resilient as possible.

The results of this success is that these farms provide commercial dividends and social benefits back to shareholders.

\section{Opportunities goals and targets}

The opportunities for Māori organisations differ depending on where each entity sits within its stage of development.

1. For those entities that are still in the underdeveloped category, the challenges are greater than those of the developing and fully developed groups. Without internal change, these groups need to assess their options to develop by drawing on the experiences of other developed Māori entities. There are opportunities to access the skills and resources of these entities to help them develop. I have seen examples of leasing arrangements, partnerships and joint ventures that have proved successful for similar groups challenged to develop their resources. These lease, partnership and joint venture arrangements will require some trusted advice, courage and sacrifice by these leaders in the medium term.

2. For the entities in the developing category, the level of success will depend on the commitment of the ownership base and governance and a properly forecasted development programme. The capability of the management and project team, and the design and effectiveness of development will dictate the end result. There are templates in Māori agribusiness

Table 1 KPI's of the last three winners of the Ahuwhenua competition.

\begin{tabular}{|c|c|c|c|c|c|c|c|c|}
\hline Property & Year & Eff. ha & SU Total & SU /ha & $\begin{array}{c}\text { Lambing } \\
\% \mathrm{~S} / \mathrm{S}^{1}\end{array}$ & $\begin{array}{l}\mathrm{GFI}^{2} \\
\$ / \mathrm{ha}\end{array}$ & $\begin{array}{l}\text { GFE }^{3} \\
\$ / h a\end{array}$ & $\begin{array}{c}\text { Farm } \\
\text { surplus } \\
\text { \$/ha }\end{array}$ \\
\hline Waipapa Station, Taupo & 2011 & 1100 & 11775 & 10.7 & 125 & 920 & 613 & 307 \\
\hline Tarawera Station, Napier/Taupo & 2013 & 2865 & 29303 & 10.2 & 137 & 1096 & 451 & 589 \\
\hline Mangaroa Station, Wairoa & 2015 & 1250 & 12665 & 10.1 & 144 & 907 & 446 & 378 \\
\hline
\end{tabular}

${ }^{1}$ S/S - Survival to sale

${ }^{2} \mathrm{GFI}$ - Gross Farm Income

${ }^{3}$ GFE - Gross Farm Expenses 
that have worn a successful development pathway. The proven basics of "subdivision and water, fertiliser and stock systems" have been a reliable and low risk recipe for most developments I have observed. I also see potential to follow partnership arrangements, where shared resources and proven management skills can reduce the risk for the developing partners.

3. For the entities in the intensifying category, the opportunities lie in optimising feed supply and quality at critical periods. Already many of these farm businesses are achieving high lambing percentages $(140 \%+)$. While there is still potential upside here, the real challenge and opportunity is to lift lamb weaning weights on these hill systems. Tools such as the use of tactical nitrogen $(\mathrm{N})$ are still opportunities used in moderation in some of these systems. The opportunity to finish these increased lamb numbers will need formal contractual arrangements with finishers, or the use of alternative land classes. Some of these entities have acquired finishing land to achieve this end, while others have identified suitable land classes within their existing entities and developed separate finishing units. A few have added or intend adding irrigation. Integrating specialist breeding and finishing farms has some merit. However, the complex skillsets required for highly intensive finishing farms differ markedly from the skillsets needed in sheep and beef breeding systems. There are opportunities for Māori to collaborate in stock supply arrangements. Some Māori groups are already developing relationships to look at in market supply arrangements.

\section{Future focus}

While there is still a large potential for Māori hill farms to develop further, there are a number of farms already performing at above average levels of production. In future many of these properties will require higher levels of leadership and management than those levels accepted in the past if they are to continue to grow and prosper. The current shortage of competent farm managers with strong business skills still needs addressing. The future focus for many hill farms should not solely be on production, but also on producing consistently high quality product for sale or slaughter.

Linked with this improved performance is the opportunity to develop supply arrangements with other Māori finishing properties. There are a range of Māori farms in a number of different climatic locations across the North Island. The networking of the farms would benefit both breeders and finishers if the right linkages are made.

Future Māori marketing opportunities are realistic. Māori do have a point of difference. Intergenerational land ownership, sustainability focus and willingness to develop longer term value driven relationships set them apart from most other land owning groups. Maori will need to develop robust linkages between groups that will generate confidence to consistently supplying product to specification. As more Māori hill farmers develop and grow, the opportunity to investigate these options and become involved in the market place will become more apparent.

These on and off farm opportunities will involve a change in behaviour on farm and a motivation from likeminded Māori leadership and facilitators to work together and make it happen. 